\title{
The Effects of Colors on the Quality of Urban Appearance
}

\section{Marjaneh Naderi Gorzaldini}

\author{
A Faculty Member Vocational College of Alzahra, Exclusively for Women, of Babol, Mazandaran, Iran \\ Marjanehnaderigorzaldini@gmail.com
}

Doi:10.5901/mjss.2016.v7n5p225

\begin{abstract}
Today, colors play a major role in elevating the quality of urban environment, by providing a milieu for citizens' interactions in public places. Public places are considered as one of the important components of urban design. Utilization of colors in urban spaces creates a sensation full of vivacity and calmness on the citizens. Designers' innovative use of colors in urban spaces, enlarges observers' perception of the surroundings. Colors can be considered as important constituents for shaping identity and creating a favorable and unified space in urban areas. This article, with reliance to the theories of urban design, investigates the impacts of colors on the qualitative indicators of urban landscapes, and the goal is to reach some basic criteria for purposeful utilization of colors in urban areas. The method of investigation for this article is descriptive-analytic, and data gathering is based on library research. The results have shown that colors are the most pivotal elements which can create unifying atmospheres, or distinguish and differentiate places from each other. Therefore, for correct use of colors in urban spaces, designers and planners should plan a comprehensive color pattern, based on scientific research and expert analysis. To achieve this mean, regional conditions, native features of the region and local identity should be considered by the designer.
\end{abstract}

Keywords: Color, Urban Landscape, The Visual impact of color, Quality of the Environment, Urban Spaces

\section{Introduction}

Improving the quality of surroundings (environments) is considered as central concepts and issues in urban design. Many pundits believe that the qualitative improvement of surroundings is the most important obligation in urban design activities. Since human's psychological needs, in connection with the environment, includes perception of the space, sense of belonging, and sensing beauty-and all these factors can create comfort, pleasure, security and satisfactiontherefore, as one of the most important visual components, colors do have a very high position; this is emanating from the fact that, they can aid us to make a desirable image of urban spaces, and thus, enriching citizens' experiences in public places of the city.

Human's perception and discernment from his surroundings consists of three stages, which the first is color, the second one is form and mass (volume), and the third one is related to the symbolic aspects of the shapes which are created by colors and masses. The aesthetic experience would be perceived in very early stages of consciousness which is related to the color factor. Favorable cities, which have visual beauties, not only constitute proper places to resolve physical needs of the citizens, but also have the power to extend the aesthetic experience by satisfying the spiritual, psychological and Cultural needs. Since the citizens are involved in an ongoing engagement with urban spaces, thus, colors' suitable applications should be considered in correlation with psychological states of the citizens.

Colors' appearances can be seen in different elements and spaces in the city. Rational and proper use of colors propels the city towards a non-confusing panorama, which can bring order, balance, comfort and equilibrium to the citizens. Humans always used colors for their symbolic and ritual roles in cultural and intellectual structures of the societies; as from the distant past, in addition of decorating buildings, colors had been used to convey particular messages. Also, color can be a tool for preservation of identity of a city; therefore, its usage should be based on spatial qualities and local features of the area. The present article studies the effects of color on the quality of urban landscape and investigates the issue of color management and the effective factors for obtaining cities' color palette.

\subsection{Methodology and Research's significance}

Nowadays, the improper use of colors in urban spaces has led to a visual confusion. Colors can reinforce the visual and intellectual aspects of urban landscape, and create a desirable and pleasant atmosphere, where no visual abnormalities can be found. As a result, urban areas' managers and planners should provide a comprehensive color plan with an 
aesthetic and comprehensive approach towards colors' application in urban places. The method of investigation for this article is descriptive-analytic, and data gathering is based on library research. The importance of this research lies in the fact that it foregrounds the importance of the concept of tint and color in urban modern world. It also declares that excessive attention should be paid to colors in urban spaces in order to provide psychological serenity for the citizens. With the use of recent scholarly works in the field of urbanism, this article tries to insist upon the fact that urban planners should pay attention to how to approach the concept of coloring in urban areas.

\section{The Definition of Landscape}

In Simon Bell's view, landscape is a process between physical and non-physical space; he writes: "landscape is that part of the surroundings which we inhabit in, and savvy it based on our senses" (Bell, 2003, p.91). Landscape is the obvious feature of an area which includes: physical elements, form of the land, form of waters like rivers and lakes, animate elements, land covers like vegetation, the things which are made by humans like structures and buildings, and temporal elements like light and weather. The synthesis of these elements with the presence of humans, creates a landscape which is the reflector of the synthesis of human life and the place. "surroundings and their features determine our perception of the place" (Seifodini, 2012, p.3). But, different people have divergent opinions about the notion of landscape. This is due to the fact that each landscape is seen and experienced in an independent cultural unit and each nation has made its own landscape based on their own cultural and historical merits. In today's world, landscape is an animate and living being which has affected by human beings, and manifests what happened in it throughout history; thus, a landscape cannot be considered as a soul-less mass, because it has both quality and meaning, altogether. Also, it should not be considered as a mere concept, because at the same time, it has body and sense; therefore, "landscape is a phenomenon which emerges from our notion of surroundings and our intellectual interpretation. In fact, landscape is a phenomenon which is both visual and intellectual" (Atashinbar, 2009, p.49).

\section{Urban Landscape}

An urban landscape is a visual reality which is perceived by each person's observance from the various elements in the city. It can be asserted that the urban landscape shapes from surroundings' visual and non-physical materials, and it constitutes all information which exist in space, and which is perceived by human's senses. Many Pundits believe that the essence of urban landscape is visual, and in correlation with the cognitive process of perceiving the environment. As Jahanshah Pakzad writes about this matter: "urban landscape is that part of the environment, or city's shape, which affects the individual's interactions, and the results of those interactions" (2006, p.101). Based on Gordon Cullen definition, an urban landscape is "the art of unifying vision and structure to the collection of buildings, streets and the places which are installed in urban environments" $(1998$, p.1). Kevin Lynch, also, thinks of urban landscape as a virtual phenomenon: "city is like an exquisite architectural monument which rises from the space, with the difference that city has a larger scale, and it needs time to find its form" (2012, p.9). Lynch also argues that the animate factors in urban areas have the same impact as the in-animate factors in shaping the urban landscape. Kourosh Golkar claims that "urban landscape is a tool which Phenomenalizes the city; in other words, the designs of the designers and architects can only become a real and humanistic experience in the light of urban landscape" (2006, p.38). In Golkar's view, urban landscape is a mixture of visual landscape, intellectual landscape and emotional landscape.

The frequent presence in urban environment, unconsciously, shapes citizens' environmental behaviors. Human brain creates virtual image of the city, based on its experiences, memories, historical events and previous emotional impacts; in this regard, not only citizens' behaviors take place in urban environments, but also, they shape urban spaces; because creating meaning is a process which is both subjective and creative. In this process, "vision and mind form a unity, and mind creates a world which it perceived through the process of perception" (Siafzadeh, 2013, p.31). In this respect, urban landscape can be considered a two-dimensional case "which in one aspect it is about the sensible and visual factors, and in another, it is about the intellectual factors of the space like history, memories, identity and such" (Eslamirad and Ghasemi, 2010, p.7). Thus, urban landscape becomes a "phenomenon which is resulted from the interactions between the sensible and nonsensible factors of the city" (Atashinbar, 2009, p.50).

\section{The Importance of Color}

The creation begins with color; and color, in its infinite variations, "causes seeing, perceiving and recognizing things and their significance" (Ayatolahi, 2002, p.7). Color is the most amazing trait of existence. Humans derive all their knowledge 
and experience base on the two elements of form and color. "Everything in the environment, firstly, perceived by its color and then by its form" (Nami, 1992, p.28). Therefore, color is a seminal factor that can differentiate how an object can be viewed; in fact, "colors endorse the pleasure of viewing the natural phenomenon, and arrange or balance the pictorial confusion" (Varamini, 2009, p.28).

"Color importance in life, brings various meanings and concepts to human's mind" (Hoseinirad, 2005, p.98). Also, color is one of the main visual stimulus, which has a close connection with human's affections and sentiments. "Colors, not only have general connotations, but they contain secret meanings also" (Dandis, 1990, p.88). Colors, with their special concepts, have penetrated in our life "in a way that we cannot define our activities without them" (Ayatolahi, 2002, p.8).

\section{The Essence of Color}

Colors are considered as light waves which are certain types of electromagnetic energy. "In 1676, Isaac Newton, with the aid of a prism, decomposed the white light of the sun into a spectrum of colors" (Aghakhani and Montazeri, 2008, p.16). Newton's experiment elucidates that the difference in the colors of the spectrum emanates from the difference of the wavelengths. Light has a wavelength between 380 to 760 Nanometers; the waves, which are out of this range cannot be seen. A person can perceive a color from the wavelengths which hit his eyes' retinas. When the light hits an object, the object absorbs all the colors of the spectrum and then reflects one color, which the human's eye transmits it to the brain through a complex process (Nami, 1992, p.83).

The human eye differentiates colors based on three characteristics: colour, blaze and saturation. "Colour is a characteristic of color, which locates the actual color from the spectrum of red to purple. Blaze determines the relative degree of blur and the lucidity of color. Saturation specifies the amount of purity of color" (Pakbaz, 2000, p.264).

\section{Physiological and Perceptual Effects of Colors}

Human's reactions towards colors are both physical and mental-emotional. Colors can arouse feelings of serenity, sadness, lethargy, and vivacity in human beings. The psychological approach to the subject of colors, investigates the feelings which are aroused by observing a particular color; for example, blue, purple and green are considered colder colors than orange and red. Warm colors are known as exciting and stimulating, red is known to arouse the most excitement in human beings.

There have been many experiments on colors until now, and the results have not been the same; but they were, somehow, near each other; for example, heart rate and breathing are measured with the radiation of different colors and usually the following results occurred: red - fast; green - calm and orderly; white - calm but erratic. Moreover, in a place which was lighted with yellow light, the lowest possible mistakes had occurred, and in contrast, in a place with blue color, maximum mistakes had occurred. This is such an interesting case because at that same blue spot intelligently works had occurred. "Colors can also have different effects on our emotional ranges" (Ayatolahi, 2002, pp.119-120).

It should be stated that the expressive characteristics of colors cannot be easily categorized; as an instance: red has characteristics like self-reliant, dominant, powerful, energetic, active, full of life and rebellious. At the same time, red can be annoying, and trigger anger and turmoil. On the contrary, blue color's characteristics can be considered as calm, thought provoking, logical, even tempered, tender and trustworthy. Yellow color also has these two-fold characteristics; it has energetic and appealing qualities, and at the same time, it can be flimsy and fragile. At its purity, yellow can be a symbol for wisdom and knowledge. "Yellow is a color which is both attractive and flexible, but it can fall from grace quickly and its energy fades away" (Hoseinirad, 2005, p.119).

We can assert that, at the primary level, the psychological effects of a color results from the innate characteristics of that particular color, and in secondary level, it relates to the psychological structure of mind, personal feelings and experiences, and childhood memories of the observing person; Geographical, cultural, historical and economical factor are on the third level of importance. Also, "the meanings and concepts which are annexed to each color is something arbitrary, therefore one color can arouse diverge emotions in different persons simultaneously" (seidsadr, 2007, p.135).

\section{Color's Application in City}

Color is an important aspect of urban life, and forms, dimensions, gender and texture are defined under the color's influence. In an urban environment, "colors can be found everywhere in bodies and the views of buildings, on the covers 
of the roofs, in urban furniture, in parks, car, and even on people's clothes; all and all, have important roles in determining the visage of the city" (Mortezaei, 2002, p.107). (Figures 1 and 2)

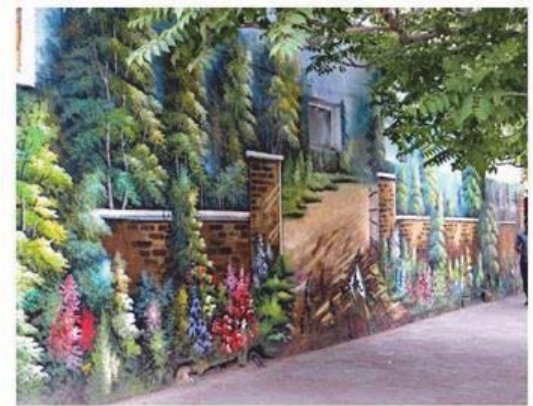

Figure 1: Color exploitation in Painting urban structures

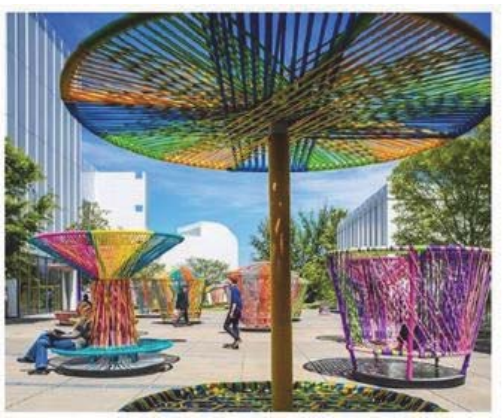

Figure 2: Colors' application in urban furniture

The correct application of colors in urban spaces aids the citizens to find and locate their needs conveniently across the city; some places like phone booths, bus stops, electronic equipment and other facilities are identifiable in urban spaces based on their colors. Colors have a pivotal role in creating a good impression of people's minds. In truth, colors shape the foundations of urban landscape; in this way, in the complex world of colors "the task of urban designer is to answer the human needs by simplifying the urban elements for citizens" (Mahmoodi and Shakibamanesh, 2005, p.112). Citizens have different expectations from different places in the city and coloring can be an important asset in this regard; for example, "the increase in the color density in intersections and boulevards, leads to awareness that these areas are more populated than the rest" (Hoseinion, 2001, p.15).

Today, as a result in the growth of communications, color is considered as a phenomenon, and in this respect, each color is used for particular purposes. We have to consider that, we cannot only pay attention to the cold and warm characteristics of colors for categorizing them in urban environment; in such fields, like urbanism and architecture, no color is defined solely, but they are defined in connection with other colors. Being cold or warm, happy or lugubrious, is not only bound to one color spectrum; it is also depending on such factors as color usage, the type of color and painted surface, being matt or shiny, and the connotations of that particular color (Navayi, 2010, p.12). Therefore, the correct color planning for urban spaces should be due attention to such effective factors.

\section{The Effect of Color on the Identity of the Urban Landscape}

Identity is the unique characteristic of a place which differentiates that particular place with other places. In other words, Identity is a feature that comes to mind by comparing a phenomenon or picture with the other instances. The new approach in urbanism has led to the increasing attention in due to the concept of identity. Urban identity is under the direct influence of culture, and natural and synthetic shapes of the city. "An identity can be assumed for cities and living environments which constitutes historical, cultural, natural, structural and humanistic identities" (Rezghi, 2013, p.53)

Creating an identity, and determining a landscape are two most important goals in urban design which color can be an important asset. The right application of color, in due attention to climate-environmental features of the cities, can play a deterministic role in the identity of the city. As Bahreini Pinpoints: "from the ancient times, urban spaces are exploited colors as decorations or message conveyors. Color usages were based on the factors such as religion, environment and tradition. Also, the geographical conditions, and other limitations, as well as the symbolic and metaphoric languages, were determined the colors' applications in the cities" (1998, p25).

In old places and structures, natural colors-which covered the buildings-have given a coordinated and homogeneous look, which was conformed with the culture and spirit of the local people. Thus, each city developed a color-certificate which differentiated it with other cities' color identity; in those cities, the religious sites, particularly with turquoise tiles, shined in the center of the cities. "Cities in the desert, with blue sky, green trees, soil buildings and turquoise domes, had made eye-catching visuals in the minds and memories of the observers" (Mortezai, 2002, p.109). (Figure 3) 


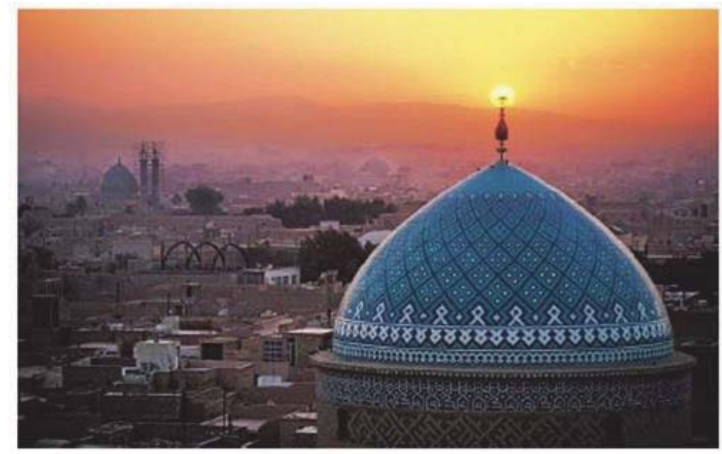

Figure 3: Using turquoise tiles in giving unique identity to religious structures

In today's world, the misuse of colors in many cities has led the color canvas of the city to such disarranged and confused state which caused a visual disturbance in urban spaces, thus, made a negative impact on the spiritual and mental tranquility of the citizens. Since, colors are connectors of the old and new economic, cultural and social values, therefore, for boosting the urban identities and developing the color palette of the city, some regulations should be put based on the society, culture and history of the regions.

\section{The Effects of Colors on Readability of Urban Landscape}

The reinforcement in visual clarity (or the readability of urban landscape) is the most important goal in urban design and management. Lynch asserts that "readability is a quality which leads to better understanding of urban components. All parts of these kinds of cities, can be disintegrated, or imagined as a whole, at the same time" (Lynch, 2013, p.12). Readability is an important criterion for reinforcing the quality of urban landscape; also, color is the most important element which can unify the space as well as give it a unique look.

\section{Color's Effects in Diversity and Vitality of Urban Landscape}

Diversity is considered a desirability index in urban landscape. Simon Bell writes about this matter that "diversity relates to the variety in design or landscape" (Bell, 2008, p.134). In his opinion, variety should be balanced with uniqueness, because so much plurality may lead to visual revolt. The lack of vitality and diversity, unintentionally, may hinder the presence of the people in urban spaces. Since a favorable environment aids the mental health of the citizens; therefore, colors can play major roles in creating a diverse and joyful environment. As an instance, in commerce streets and children's playgrounds, color variations have been exploited in order to create happy and joyful spaces. Even "the special occasion through-out the year have different variety of colors than the rest of the year; joyous ceremonies and galas are known with their abundant colorings during days and nights" (Mahmoodi and Shakibamanesh, 2005, p.117). (Figure 4)

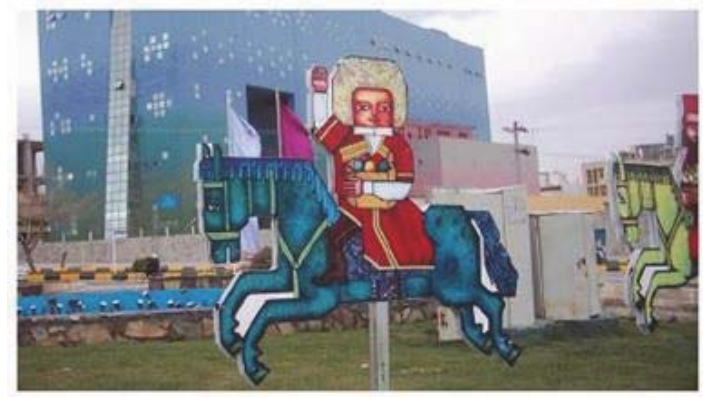

Figure 4: Strengthening of happiness in urban spaces using coloring 


\section{The Effect of Mobility in Color Perception of the City}

Since our experience of urban environment is a dynamic one, thus, our aesthetic experience in urban spaces becomes an important aspect of visual perception. "The environment is experienced as a dynamic and transient scene" (Motevali, 2010, p.136). A city is constituted of network of consecutive spaces which has different visual qualities. These sequences in spaces, happen when a human on a route, perceives each distinct and individual spaces and considers them as related. The spaces which exist in this endless composition, cannot be observed concurrently, thus, they have to be perceived in consecutive visions. By passing through these spaces, citizens perceive various impressions by receiving different sensations about their experience. "This concept is important because citizens are moving in the city most of the time" (Hoseini and Razaghi, 2008, p.87). Each time, the movement makes new vision, and this leads humans to experience successive and relevant visions; ergo, these successive visions are enhanced by moving from place to place and creates an enormous three dimensional effect in the observer; in these "consecutive visions, the observer experiences ebullient emotions as he moves in urban spaces" (Motevali, 2010, p.124). Therefore, in city's color design, all the spaces (roads and pedestrians) should be considered in planning, because many movements occur in the intersections. One of the most important theories in visual sequences' theories, is Gordon Cullen's theory of "consecutive visions." He believes that "although pedestrians walk through the city with a similar pace, but, actually, urban landscapes take shape in form of a cluster of urban elements which are consecutively revealed and come forward in front of the observers" (Cullen, 1998, p.20). The quality of citizens' impressions from the urban landscape depends on the pace of their movements; as an instance, pedestrians can have a better grasp of urban landscape that those who travel by buses, cars, etc. Therefore, designers should consider speed and color in their urban design. For example, in a highway, because of the vastness of the spaces and the speed of automobiles, big simple colorful spots should be used for guidance; because small detailed spots may distract the drivers, and distort these kind of spaces. In contrast, "in a sidewalk which is designed for pedestrians, the smaller scale allows the designer to go through details and create a more colorful place, in order to communicate further with citizens" (Mahmoodi and Shakibamanesh, 2005, p.199).

\section{Color Management in City}

Due to the importance and necessity of color application in urban spaces, the correct exploitation of these spaces should be considered by planners and urban managers. Jean Phillip Laanco is among the researchers which has done vast investigations in this particular field. He has investigated on a suitable color template for urban spaces and, thus, proposed the following considerations:

1) The Analysis of principal colors of the districts (Nature, herbs, soil, etc.).

2) Determining the qualitative and quantitative relation of colors in different architectural elements in the city; in this stage, the color range of structures and other elements in urban environments (Like doors, windows, furniture, etc.) are evaluated and categorized.

- Testing and research on the district (taking some samples of materials and colors of the region).

- Analysis of the gathered data, which includes palette of environmental colors, palette of artificial colors, and architecture of the district.

- The result of the research is to propose a color palette for each region (the colors with accord and discord can be divided into two separate categories in order to help the planners and designers for future projects).

3) The last stage is to provide a color table which presents the exact color quality of each region; and with these colors, numerous mixtures can be created. Each color plan has consisted of two main palettes:

A) The primary system which presents harmonic colors for big spots and architectural surfaces.

B) A bigger system which constitute of more extended natural and architectural samples; like flowers and other mobile objects which are situated in urban environments. Laanco also investigated the colors which confront each other in color cycle. He "calls them opposite colors; but when these colors come beside each other, their effect would be intensified" (Mortezai, 2002, pp. 120-122).

Regardless, it should be asserted that the urban designers should consider the following procedures for developing a color pattern for cities:

1) Preparing a color map of the city by taking color samples from each district.

2) Understanding the deterministic features of color map of each region, like light quality, traditional colors, and cultural preferences of the people.

3) Determining the extension of each region in accordance to capacity, applicable needs, and other aesthetic 
measures.

4) Developing some ground rules for protecting the color identity, and regaining the lost color features of the city in order to protect the physical and cultural characteristics of each region. "This goal can be achieved by application of particular signs and furniture throughout the city" (Hoseinion, 2005, p.51).

\section{Conclusion}

Based on the opinions of designers and experts in urban industries, colors are considered as pivotal factors in architecture and urbanism. Therefore, for determining a color plan for a city, a kind of strategic policy should be adopted. An urban designer should design 'the comprehensive color plan' of the city, based on the meticulous researches and investigations. In this regard, climate conditions, native features of the place, and historical and cultural identity should be considered by the designers. In general, the effect of colors' application in urban spaces can be summarized as follows:

- Colors and paintings are considered as important factors which can give a new image to cities as well as boosting the visual and intellectual aspects of urban landscape.

- The Colors in a desirable city, have a harmonic and specific sets of range and, mostly, are balanced in accordance to each other.

- The proper application of colors strengthens the visual qualities in the city, and creates a sort of calmness and balance in urban spaces and, thus, lessens the psychological damages which are influenced by visual pollutions.

- color is a tool for safekeeping the identity, feeling and readability of urban spaces.

- In an urban area, colors help the citizens to identify different occasions and rituals.

- Color usage in urban spaces, helps the observer to easily distinguish the spaces and environments from each other.

- Color can make structures apprehensible, and illustrate their usages and values.

- In addition to beautifying a place, colors can be used also to convey certain messages.

- Colors can diversify the experiences in the city, and stimulate citizens for more active life.

\section{References}

Aghakhani, H. \& Montazeri, A. (2008). Foundations of Visual Arts 2. Tehran: Payam Noor. Atashinbar, M. (2009). Consistency of identity in urban landscape. Bagh Nazar, 6(12).

Ayatolahi, H. (2002). Colors' fundamentals and their applications. Tehran: Samt Publications.

Bahreini, H. (1998). Urban Design Process. Tehran: University of Tehran Publication.

Bell, S. (2003). Perspective, Pattern, Perception, and Process. Tehran: University of Tehran.

. . . . (2008). Visual Design Elements in Landscape. Tehran: Khak Publication.

Cullen, G. (1998). A Selection for Urban Landscape. Tehran: University of Tehran.

Dandis, D. (1990). Basics of Visual Literacy. Tehran: Soroush Publication.

Eslamirad, G. \& Ghorbani, Y. (2010). The Importance of Historical Parks in Urban Landscapes. Pazhoheshkade Farhang and Honar.

Golkar, K. (2006). The Concept of Urban Landscape. Nashrieh Abadi, (53).

Hoseini, B. \& Razaghi, S. (2008). Motion and Time in Urban Landscape. Architecture and Urbanism, (6).

Hoseinion, S. (2001). Color in City from Urban Design Perspective. Mahnameh Shardariha, (39).

. . . . . . (2005). Recreating City in Color. Mahnameh Shahrdariha, (72).

Hoseinirad, A. (2005). Visual Arts Fundaments. Tehran: Chapo Nashre Ketabhaye Darsi.

Lynch, K. (2012). A City's Visage (11th ed.). Tehran: Samt Publication.

Mahmoodi, K. \& Shakibamanesh, A. (2005). Chromatics principles in architecture and urbanism. Tehran: Heleh Publication.

Mortezai, R. (2002). Approaches in the design of urban furniture. Tehran: Sazman Shahrdari Keshvar.

Motevali, M. (2010). Review and assess the aesthetic quality of the urban landscape, on the basis of consecutive views. Faslnameh Armanshahr, (5).

Nami, G. (1992). Fundaments of Visual Arts. Tehran: Toos.

Navayi, H. (2010). The role of color in today's social context. Mahnameh Manzar, (10).

Pakbaz, R. (2000). The Encyclopedia of Art. Tehran: Contemporary Art Publisher.

Pakzad, J. (2006). Theories and Processes of Urban Design. Tehran: Ministry of Housing and Urban Development.

Rezghi, M. (2013). The Analysis of Urban Spaces. Tehran: Avalo Akhar Publication.

Seidsadr, A. (2007). Architecture, Color and Human (3rd ed.). Tehran: Asar Andisheh.

Seifodini, F. (2012). Urban Landscape. Tehran: Ayizh Publication.

Siafzadeh, A. (2013). Role in creating quality urban landscape of social life and identity of place. FasInameh Moteleat Shar Eslami, (11). Varamini, N. (2009). Creative Thinking in graphics (2nd ed.). Tehran: Mirdashti. 